\title{
Application of MOOC and Virtual Simulation Experiment in Experimental Teaching of Mechanical Design
}

\author{
Shaoyong Han ${ }^{1,2}$, Jingchun Zhan ${ }^{1,2}$, Zhen Wang ${ }^{3 *}$ \\ ${ }^{1}$ School of Information Engineering and Technology, Changzhou Institute of Industry Technology, \\ Changzhou, Jiangsu, China \\ ${ }^{2}$ School of Computing, Faculty of Engineering, Universiti Teknologi Malaysia, \\ Johor Bahru, Johor, Malaysia \\ ${ }^{3}$ School of Data Science and Artificial Intelligence, Wenzhou University of Technology, Wenzhou, \\ Zhejiang, China \\ *Corresponding Author
}

\begin{abstract}
:
The mechanical design experiment is a comprehensive experimental course that can cultivate the preliminary engineering practice ability of machinery students. Due to the high requirements for students' basic knowledge and ability of comprehensive application of knowledge, teaching is difficult and the teaching effect is general. This paper uses the MOOC teaching method, a new network-based teaching model, to study the experimental teaching of mechanical design and the construction of virtual simulation experiment teaching system under the new situation. Firstly, analyze the advantages in experimental teaching of mechanical design under virtual simulation experiment. Secondly, it puts forward suggestions for constructing the virtual simulation experiment teaching system of mechanical design, and discusses the advantages of the combination of MOOC and virtual simulation experiment technology, opportunities and reforms under the new situation. Lastly, it can be concluded that by using MOOC and virtual simulation experiments can break through the limitations of traditional teaching and improve teaching. This paper applies the MOOC and virtual simulation experiment to the experimental teaching of mechanical design, can not only improve the teaching of teachers, but also cultivate the practical ability and thinking innovation ability of machinery students. With the advantages of MOOC and virtual simulation experiments, it provides better opportunities and challenges for the teaching of mechanical design.
\end{abstract}

Keywords: MOOC and virtual simulation, Mechanical design, Experimental teaching, Teaching method 


\section{INTRODUCTION}

MOOC, a massive open online courses, which is a form of online course development that has emerged in recent years [1]. The essence of MOOC is developed from online courses, video courses and Internet-based communication platforms, emphasizing scale and openness [2]. Most of them can only provide online theoretical courses for students, lack of experimental links, which brings inconvenience to some subjects combining theory and practice. Therefore, how to carry out experimental teaching in MOOC is a big problem we are facing. Virtual simulation experiment technology is an emerging electronic experiment platform that has emerged with the rapid development of science and technology and network technology. It can realistically simulate real experimental scenes and perform experimental operations on a computer. The joint application of MOOC and virtual simulation experiments realizes the complementarity of superior resources [3]. Virtual simulation experiments can complement and improve the course of organic theory [4]. The virtual simulation experiment uses virtual reality and computer simulation, multimedia and other modern technologies and interactive modes to simulate the experimental environment and operation objects through virtual height, so that the experimenter can complete all the scheduled experimental projects and meet the requirements of the syllabus and the goal of talent training [5]. In particular, it can avoid the loss caused by high-risk environment and irreversible operation, and save the cost of large-scale experimental projects with high cost and high consumption.

At present, most engineering colleges still use the combination of classroom theory teaching and experimental courses for mechanical design. Some colleges and universities have begun to record and use online courses, but rarely use virtual simulation experiment teaching to assist theoretical teaching. Today, college students are increasingly interested in emerging technologies and methods [6-7]. Computers and mobile phones have become an indispensable tool in their life and learning, and they are skilled in operating various software or mobile applications. However, some teachers still follow the original teaching mode, blindly instilling boring knowledge points into students, and even do not combine life examples, which makes it difficult for students to concentrate in the classroom and it is difficult to achieve good learning results [8]. In addition to theoretical teaching, many of the analysis involving large instruments are not used because of the shortage of funds in schools, and the use of less, so that students do not have their own hands-on opportunities, only imagination or video learning, lack of practice, the students are not in the actual operation, so the learning effect is not very ideal, and the test results show that there is no good teaching effect [9].

For the moment, we should make full use of the advantages of online education and use 
virtual simulation experimental techniques to provide students with more practical opportunities. This reduces the consumption of resources, reduces the cost of teaching, and also avoids various security risks in the experiment [10]. The use of MOOC and virtual simulation teaching can effectively avoid this problem, reduce environmental pollution, and achieve green teaching [11]. Through virtual simulation technology, students can rely on a single computer and a set of virtual simulation software to complete the traditional experiments that require many technical equipment. This broke through the barriers of the classroom and teachers, and the experimental results were optimized [12].

This paper uses the network-based classroom teaching as a new teaching mode. The virtual simulation mechanical design experimental teaching under the new situation, the experimental teaching system is constructed. Firstly, the advantages of virtual simulation experiment mechanical design experimental teaching are analyzed. The proposal and discussion of constructing the virtual simulation experiment teaching system of mechanical design, the combination of class and virtual simulation technology, reform and opportunities under the new situation. By enriching the content of the virtual experiment project, the 3D virtual experiment is more realistic, and the experimental steps are demonstrated from many aspects and multiple angles. In engineering practice, it is necessary to combine the MOOC and virtual simulation experiments to carry out experimental teaching and learning, but virtual experiments cannot replace actual experimental conditions and environments. The virtual experiment will eventually return to the original real mechanical design experiment to verify.

\section{PROPOSED METHOD}

\subsection{MOOC and Mechanical Design Experiment Teaching}

With the acceleration of the socialization process, the educational approach has also shown a qualitative increase. New forms of teaching, such as online open classes, micro-curriculums, and MOOCs, are emerging as emerging educational technologies. Among them, network technology is one of the most advantageous ways for modern education, and has been widely used in all aspects of teaching. MOOC is a large-scale online open course and a new type of educational learning model. They provide video instruction, in-class or after-school exercises, after-school online tutoring and after-school comprehensive testing, based on a certain amount of time on the web, which is similar to traditional university semester settings. Therefore, the teaching of MOOC is not only the destructive power of modern education, but also the lack of entanglement in the creation of pain education, so that students can fall in love with learning.

Mechanical design is one of the compulsory courses for engineering majors. It mainly 
investigates the students' comprehensive application ability of basic courses such as mechanical drawing, parts mapping, mechanical principle, engineering mechanics and so on. Experiment is an important part of the practice teaching of mechanical design, which is an organic combination of students' theoretical knowledge and practice. The purpose of experimental research is to strengthen the basic experimental skills of students, and to develop students' comprehensive analytical skills, problem-solving skills and engineering practice skills. For the traditional mechanical design experiments, it is generally required to support the laboratory and other related environments, but in the teaching, the experimental equipment cannot meet the requirements required for teaching, resulting in only a few students conduct comprehensive laboratory skills training. It is the emergence of the MOOC and the simulation experiment environment that is effectively alleviated in the absence of laboratory conditions.

In the traditional functional experiment teaching, supplemented by the synchronous function experiment $\mathrm{MOOC}$ online course, students can get online and offline teaching mode training, and also enable students to get theoretical and skill training in advance to improve the success rate of mechanical design experiment operation, and get better training results. For example, in the removal and installation experiment of the reducer, students are prone to errors in the installation process. However, students can observe and learn the installation process of the reducer in the early or simultaneous times through the MOOC, master the technical points and logical order of installation, improve the efficiency and success rate of installation.

\subsection{The Impact of Virtual Simulation Experiment in Teaching}

The current 3D simulation virtual experiment is widely used in laboratory teaching [13]. The current virtual simulation experiment combines a variety of virtual simulation technologies. There are different virtual experimental environments in the virtual simulation technology, which enables the students participating in the experiment to randomly select the experimental environment they need. It also allows the experimenter to perform experimental operations in a laboratory condition comparable to the laboratory's real environment.

Virtual simulation mechanical design experimental teaching mode is mainly reflected in the full pre-study before the class, so that students gradually master the experimental principles, operating procedures, precautions and so on. Only in the classroom can students have more time and opportunities to interact with other students or teachers. The function of the virtual laboratory system establishes a good platform for teachers and students to flip classes. For example, in exploring mechanical principles and normal mechanical installation regulation experiments, students can self-prepare before class, goals and subjects through virtual experiment systems, experimental equipment, according to the principles of the experiment to 
further review the knowledge of the previous knowledge of mechanical design, help to deepen students' cognitive thinking, further improve the experimental operation ability. Students watch experimental operation videos, simulate every step of the experiment during the simulation experiment, and can actually realize the actual operation in the classroom. The system effectively solves the difficulties of students' pre-class preparation. Since the complexity of the experimental content is more abstract, it is difficult for students to effectively grasp the experimental steps. The incomprehension in the experiment can also be the interaction between the target and the teachers and students. Students' self-learning enthusiasm improves the quality and efficiency of experimental teaching.

Nowadays, how to effectively add virtual simulation experiments in the experimental teaching process can significantly improve students' enthusiasm for participation and teaching quality through the virtual experimental environment. But whether it can substantially improve the overall quality of education and education progress, after all, the virtual simulation experiment is virtual, it loses the intuitiveness, stimulation and exploration of real things. The authenticity of mechanical tools is an important factor in improving students' enthusiasm for practice. Therefore, in the application of virtual simulation experiments to teaching, students' learning interest and enthusiasm are low. Therefore, the teaching of the application function experiment of the virtual simulation experiment should be improved from the following two aspects: first, enrich the content of the virtual experiment, more realistic three-dimensional virtual experiment, and demonstrate the experimental steps in various aspects and from multiple angles; second, virtual simulation experiments combined with mechanical design experiments, virtual cannot replace reality, virtual experiments ultimately require real mechanical tools experiments.

In summary, no matter from the development trend of network technology, reforming the needs of traditional basic mechanical design courses, designing and developing network open class quality and simulating virtual experiment and application function laboratory teaching is undoubtedly the hotspot and direction of practical teaching in future higher occupations. Applying MOOC and virtual simulation experiments to functional experiment teaching can lower the threshold of experimental projects, free students from the limitations of equipment and time, obtain more and better experimental projects and teaching content, and improve the quality of practical teaching. In the actual teaching process, how to control the class time ratio of MOOC, virtual simulation experiment and mechanical design experiment, coordinate the relationship between virtual simulation experiment and real experiment, improving the quality of teaching in functional laboratories is the direction of functional laboratory curriculum reform. 


\subsection{Construction of Virtual Mechanical Design Experiment Teaching System}

(1) Design virtual platform. The virtual platform includes virtual laboratory system interface and teacher management interface. The interface of the laboratory system can be used for students to select experiments and view help information. The teacher management interface helps teachers manage experimental teaching.

(2) Design virtual experiment with 3D model [14]. Aiming at several representative mechanism or machine models in the practice course of mechanical design, the 3D modeling function of software is used to make the mechanism or machine model be displayed in the virtual experimental platform of computer. Taking the disassembly and assembly experiment of the reducer as an example, the following parts should be included. First, the function description, working principle and practical application of the reducer and the name, function and design principle of each part of the reducer should be included. Second, the experimental process of reducer assembly and disassembly is realized through interaction, such as installation logic sequence, error correction prompt, etc. Third, the experimental method description document is provided, and students can fill in the experiment report online. According to the experimental course of mechanical design, various related experiments are designed for students to choose and learn.

Students can also book offline experiments through the virtual platform. Teachers manage the experimental teaching through the teacher management interface of virtual platform, such as the evaluation of experimental report, performance evaluation, online feedback and question and answer.

\section{EXPERIMENTS}

\subsection{Experimental Environment}

There are six modern mechanical design functional laboratories, including two virtual laboratories and four general laboratories. The virtual laboratory is equipped with one hundred computers and a server. The large-scale mechanical design virtual simulation experimental teaching system is connected through the teaching platform of the educational administration department. Students can not only learn functional knowledge in the laboratory, but also read and collect many experimental textbooks through mobile phones at anytime and anywhere. SPSS statistical software was used to process the data, and the processed data were analyzed again. 


\subsection{Experimental Steps}

This time, the students are in the study stage of mechanical design experiment. The experimental group and the control group were taught by the same teachers. The control group was taught by traditional teaching method, while the experimental group was taught by learning platform-MOOC class and virtual simulation experiment.

(1) Autonomous learning network platform: The mechanical engineering experiment teachers spend a lot of time recording and producing videos, including the use of some basic tools and instruments, and finally upload videos, MOOC lessons and virtual simulation experiment course ware and other learning resources of learning platform. Mechanical design experiments were carried out and three typical cases were selected. Each class is divided into six groups, and common questions are designed for students to discuss. The experimental group students use the learning platform for online learning activities. Current experiments include cognitive experiment of typical mechanical parts and disassembly experiment of reducer. The purpose is to cultivate the habits and abilities of students to learn independently. The control group used the traditional way of textbook preparation.

(2) Implement offline teaching: First, test student self-study in the classroom to test the learning effect. In the teaching process of the experimental group, teachers change the traditional inculcation teaching method into the student-centered teaching method, in other words, students use teaching methods, students discuss, teachers and students solve problems together. The control group used the method of teacher's lecture in class to teach students the experimental principle, method, steps and matters needing attention. The experimental operation of the two groups of students was conducted under the correct guidance of the teacher. The teacher discussed and summarized the experimental phenomena, and wrote the experimental report after class.

\subsection{Data Collection}

200 students of mechanical engineering undergraduates were selected, including 100 students as experimental groups. The control group consisted of 100 students. All students were engineering students, and the general data were not statistically significant $(\mathrm{P}>0.05)$.

The questionnaire was used for classroom testing, and the teaching evaluation was carried out from the aspects of group experiment success rate and mixed teaching investigation and analysis. 
(1) Student evaluation: The questionnaire survey method is adopted. The main contents include students' attitudes towards "online + offline" mixed teaching and traditional classroom teaching, their ability to accept, their role in their own development and their lack of teaching methods. Questionnaire data were descriptive statistical analysis.

(2) Total score evaluation: After completing the teaching content, the two groups of students will use the same functional laboratory test to evaluate their knowledge. The total score is 100 points, the theory is 70 points, and the project-based learning is 30 points. 89.5 100 is excellent, 74.5 89.4 is good, 59.5 74.4 is pass, and below 59.5 is fail.

\section{DISCUSSION}

\subsection{Contrast and Analysis of Student Evaluation}

100 questionnaires were sent out and 98 valid questionnaires were collected in the experimental group, with a recovery rate of $98.00 \%$. Students generally believe that mixed teaching is more suitable for them, because functional experimentalism itself involves complex theoretical knowledge, which requires students to complete by hand. Mixed teaching is beneficial for students to master knowledge systematically and cultivate students' ability and consciousness of independent learning. The details are shown in Table I and Fig 1.

\section{TABLE I. Student evaluation}

\begin{tabular}{|l|l|l|l|}
\hline Project & Sure & Neutral & Against \\
\hline Whether to accept Teaching Reform & 61.54 & 20.25 & 18.21 \\
\hline Whether to accept mixed teaching & 71.58 & 13.25 & 15.17 \\
\hline Whether Reform can Improve Hands-on Ability & 72.34 & 10.58 & 17.08 \\
\hline $\begin{array}{l}\text { Whether Reform can Improve the Success Rate } \\
\text { of the Experiment }\end{array}$ & 65.78 & 11.36 & 22.86 \\
\hline
\end{tabular}




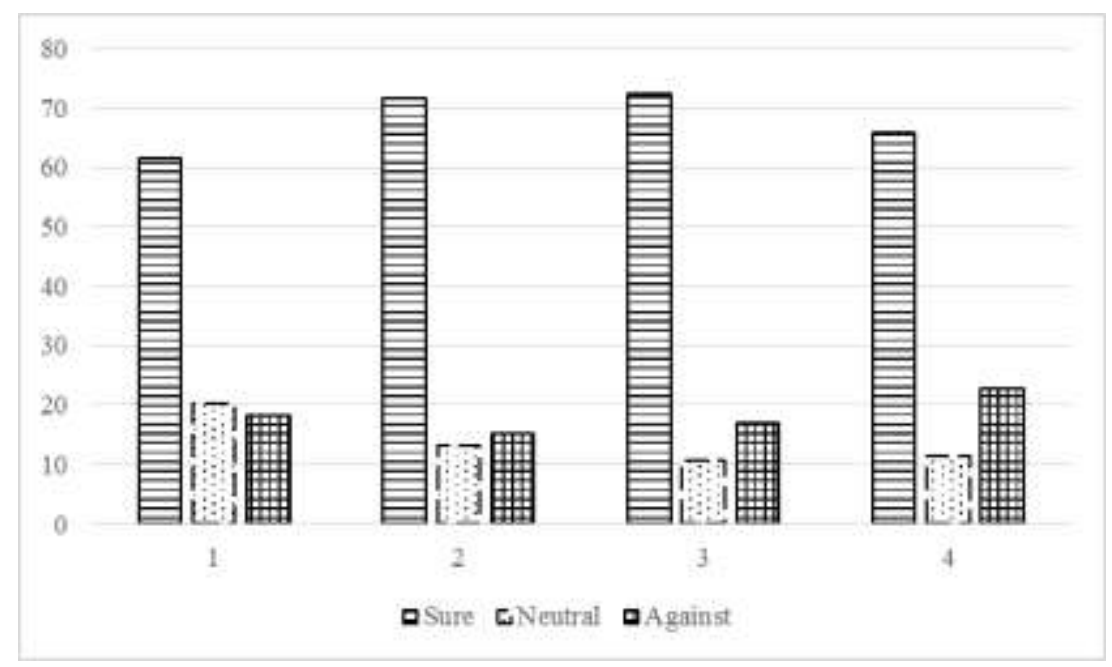

Fig 1: Student evaluation chart

\subsection{Teaching Quality Results and Comparison}

(1) The results of the final test outcome of the students showed that the average score of the experimental group (81.2) was higher than that of the control group $(72.5, \mathrm{P}<0.05)$. The proportion of excellent students in the experimental group $(67 \%)$ was higher than that in the control group $(56 \%)(\mathrm{P}<0.05)$, and the proportion of students who failed the test was only $4 \%$, which was significantly lower than that of the control group $(11 \%, \mathrm{P}<0.05)$, Fig 2 shows:

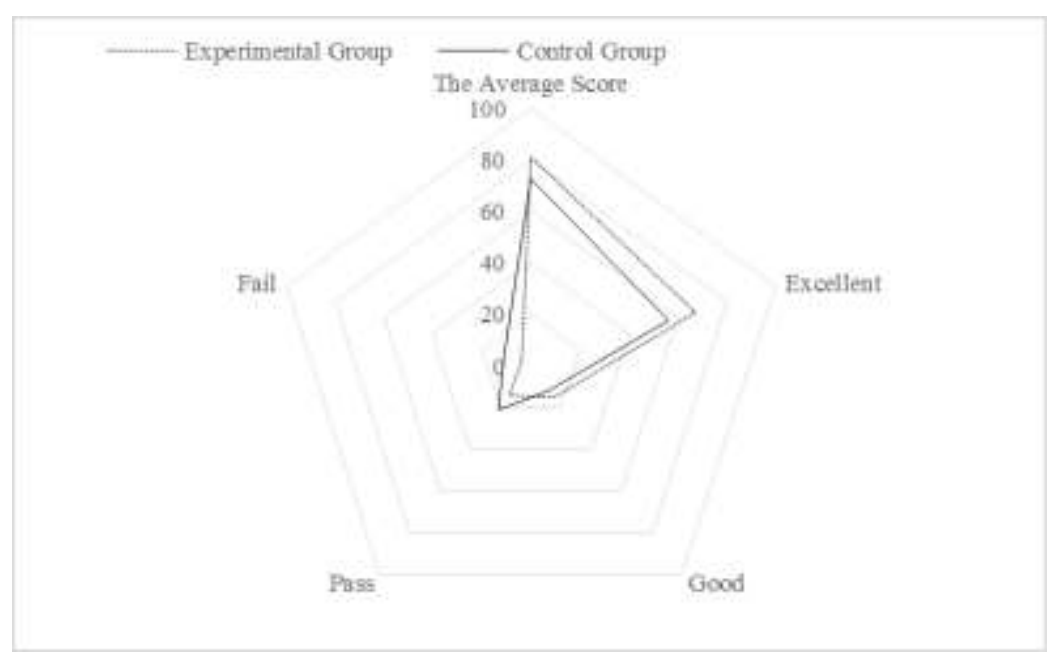

Fig 2: Two groups of students' final exam scores

(2) MOOC and virtual simulation experiment teaching is a typical process teaching, the test 
should focus on process testing and scenario testing. The two stages of design are comprehensive and multi-angle assessments from the aspects of project design innovation ability, comprehensive application of knowledge ability, literature induction and induction ability, hands-on ability, language expression and writing ability, independent analysis and problem-solving ability. In this experiment, the experimental group members were selected to score the experiment. The scores are shown in Fig 3.

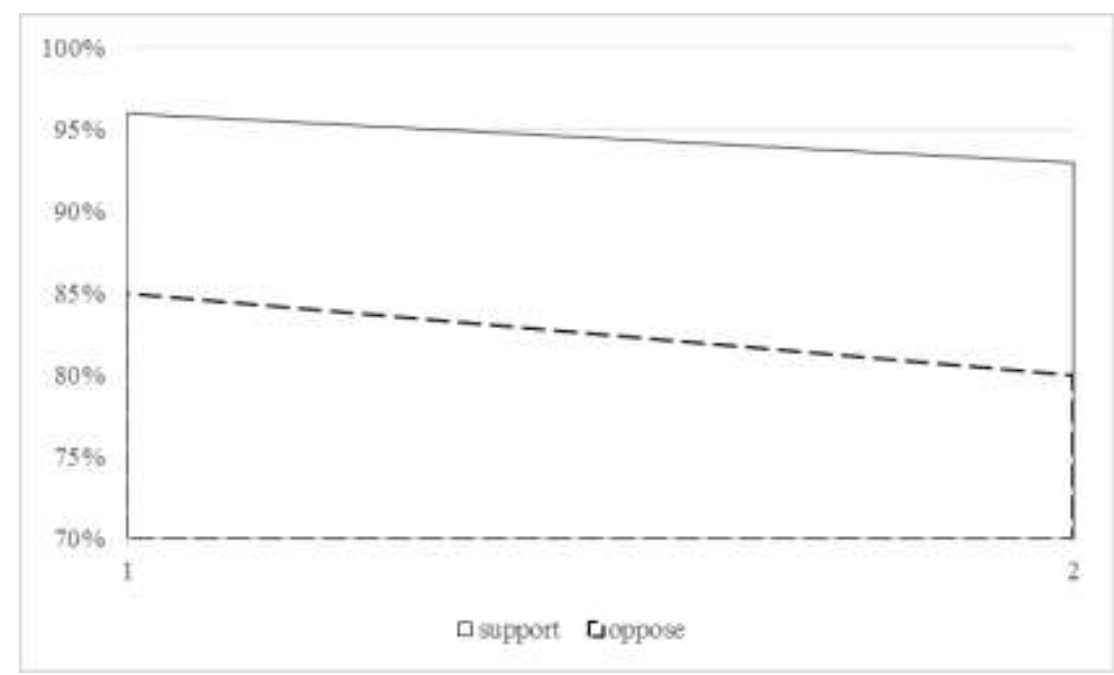

Fig 3: Experimental support rate

\section{CONCLUSION}

Through the above experiments, it can be seen that the quality of teaching is not only reflected in the objective academic achievement, but also in the subjective satisfaction of the students in the teaching effect. The feedback from the students plays an important role in improving and improving the quality of teaching. A questionnaire surveyed on the satisfaction of design experiments for 100 students in mechanical engineering. The results show that students are recognized for the experimental teaching methods using the new technology and virtual simulation experiments. $81 \%$ of the students believe that the MOOC and virtual simulation experiments are necessary in the analysis of mechanical design, and the whole process involves the design process. $83 \%$ of students believe that they have the basic ability to carry out research and design work, and the satisfaction of the course reaches $96 \%$. It shows that the teaching method of the experiment and teaching of mechanical design in the virtual simulation experiment is feasible and effective in teaching.

Mechanical engineering students are future mechanical engineer. How to better develop 
students' active learning ability in the basic undergraduate education stage is worthy of attention. How to improve the self-learning ability, engineering practice ability and scientific and technological innovation ability of mechanical engineering undergraduates is the need of the development of higher education, and it is also one of the important issues to be solved urgently. In the function experiment teaching, the experiment focusing on basic skill training is an important way to train students to master basic skills and strengthen theoretical knowledge. Traditional teaching methods are mainly taught by teachers. The teacher first explains the basic principles, methods, steps and precautions of the experiment, then guides the students to conduct experiments, and finally analyzes and summarizes the experimental results. Most of the traditional experimental teaching adopts this method, which has the advantages of large amount of information and emphasis on key points, and has a certain effect on students' indepth understanding of theoretical knowledge. The disadvantage is that the students' subjective initiative and innovation ability cannot be fully utilized, and students' self-learning ability cannot be improved. Without adequate preparation, it is difficult for students to master complex theoretical knowledge in a limited classroom time. This project has built a superstar teaching platform for online learning, and uses case studies such as case studies offline. This teaching reform takes the "online + offline" mixed teaching mode as the core, and builds a new teaching mode based on mechanical design experiments. This model provides students with sufficient preparation time, which is conducive to cultivating students' solid theoretical foundation, thus improving the teaching effect of the experimental class, and laying a foundation for cultivating mechanical engineer talents with comprehensive application analysis ability and practical operation ability.

MOOC and virtual simulation experiments in the teaching of mechanical design experimental teaching requires a high-quality teaching team, teachers must do a good job of "online + offline" teaching, with the ability to comprehensively solve problems. In addition, the new teaching methods put forward higher requirements for the evaluation system, especially the formative evaluation, including self-evaluation, mutual evaluation and teacher evaluation. In summary, mixed teaching can give full play to the leading role of teachers, ensure students' subject status, mobilize students' enthusiasm, initiative and creativity, and improve students' ability to use the knowledge they have learned to solve practical problems. Studies have shown that MOOC and virtual simulation experiments are effective in the teaching of mechanical design experiments, which can significantly stimulate students' interest in learning, cultivate the comprehensive ability of knowledge self-construction, improve information communication and sharing awareness, and improve teaching effects. In the future work, teachers also need to strengthen teaching reform, accumulate experience and improve teaching results.

\section{REFERENCES}


[1] North SM, Richardson R, North MM (2014) To Adapt MOOCs, or Not? That Is No Longer the Question. Universal Journal of Educational Research 1(1): 69-72.

[2] Mohamed G (2014) Educating rita in the time of mooc. Mechanical Engineering 136(2): 8-8.

[3] O'Malley PJ, Agger JR, Anderson MW (2015) Teaching a chemistry MOOC with a virtual laboratory: Lessons learned from an introductory physical chemistry course. Journal of Chemical Education 92(10): 1661-1666.

[4] Chen D, Kong X, Wei Q (2021) Design and development of psychological virtual simulation experiment teaching system. Computer Applications in Engineering Education 29(2): 481-490.

[5] Olszewski AE, Daniel DA, Stein DR, et al. (2018) Teaching pediatric peritoneal dialysis globally through virtual simulation. Clinical Journal of the American Society of Nephrology 13(6): 900-906.

[6] Leem J, Jung W, Kim Y, et al. (2018) Exploring the combination and modular characteristics of herbs for alopecia treatment in traditional Chinese medicine: an association rule mining and network analysis study. BMC complementary and alternative medicine 18(1): 1-13.

[7] Li SX, Y JC (2019) Study on Brain Electromyography Rehabilitation System Based on Data Fusion and Virtual Rehabilitation Simulation. Journal of medical systems 43(2): 22.

[8] Dang BK, Palicte JS, Valdez A, et al. (2018) Assessing Simulation, Virtual Reality, and Television Modalities in Clinical Training. Clinical Simulation in Nursing 43: 30-37.

[9] Mahmood T, Scaffidi MA, Khan R, et al. (2018) Virtual Reality Simulation in Endoscopy Training: current Evidence and Future Directions. World Journal of Gastroenterology 24(48): 5439-5445.

[10] Zhang Z, Pan X, Fang Y, et al. (2020) Laboratory study on the hydraulic characteristics of mechanically and biologically treated waste in China. Waste Management 102: 686-697.

[11] Kurt S (2019) The Case of Turkish University Students and Moocs. American Journal of Distance Education 33(2): 120-131.

[12] Stöhr C, Stathakarou N, Mueller F, et al. (2019) Videos as learning objects in MOOCs: A study of specialist and non-specialist participants' video activity in MOOCs. British Journal of Educational Technology 50(1): 166-176.

[13] Kim D, Ryu W, Lee S, et al (2016) A unity3d-based mobile fashion coordination system. International Journal of Advanced Media \& Communication Ijamc 6(1): 86-92.

[14] Aswale P, Mishra AK, Bharambe T, et al. (2020) Teaching-Learning Process in Engineering using Virtual Instrument based on LABVIEW 2(9): 6-9. 